\title{
EDITORIAL
}

\section{As funções e as responsabilidades dos revisores}

A revisão por pares é o principal mecanismo pelo qual a qualidade da pesquisa é avaliada. Diante do crescente aumento de artigos científicos publicados a cada ano, a qualidade do processo de revisão por pares, influencia na reputação de um periódico. Contudo, o processo de edição e de revisão de artigos não é um processo fácil. Como afirmam Silva, Moreiro-Gonzalez e Mueller (2016), a natureza da tarefa editorial é complexa e, muitas vezes, realizada de forma concomitante com a docência e com o trabalho científico. Esses autores destacam ainda a natureza voluntária do conselho editorial e de pareceristas que trabalham para a qualidade do periódico. Assim, as revistas científicas que publicam artigos revisados dependem de pessoas que normalmente oferecem seu tempo e experiência à função de vistoriar.

O trabalho do revisor se caracteriza por avaliar aspectos como originalidade do trabalho, pertinência ao escopo da revista, coerência metodológica, entre outros. Coimbra Jr. (2003) ressalta a expectativa de que o processo de revisão por pares indique a produção de pesquisas originais, evidencie erros e identifique aspectos éticos associados ao trabalho.

Apesar de ser o mecanismo padrão no qual a avaliação da comunicação científica é realizada, o trabalho de avaliação dos revisores científicos é permeado por certa subjetividade (SILVA; PÖTTKER; MOREIRO-GONZÁLEZ, 2015). Nesse contexto, normalmente, os editores das revistas enviam o manuscrito submetido a dois pareceristas e no caso de discordância o trabalho é enviado a um terceiro revisor, mesmo assim, esse sistema apresenta limites (DINIS-OLIVEIRA; MAGALHÃES, 2019). Embora o processo de revisão por pares seja objeto de críticas, apresenta-se ainda como alternativa viável para avaliação dos trabalhos (COIMBRA JR., 2003; DINIS-OLIVEIRA; MAGALHÃES, 2019), devendo-se discutir seu aprimoramento (COIMBRA JR.).

No sentido de expressar a transparência da nossa revista, nesse editorial destacamos as práticas assumidas por nossa revista na busca de uma avaliação justa e criteriosa dos artigos submetidos, mesmo quando se trata de artigos dos pares que 
pertencem ao programa. O Conselho Editorial da Revista Brasileira de Educação em Ciências e Educação Matemática (ReBECEM) tem por norma submeter a avaliação de um manuscrito para ao menos dois revisores, os quais elaboram suas avaliações com base em formulários específicos para cada seção, com critérios que norteiam o processo de revisão. Em casos de controvérsia ou desacordo de decisão dos avaliadores, um terceiro revisor pode ser requisitado. Isso objetiva fortalecer a relevância da matéria submetida, bem como verificar se apresenta forma e conteúdo apropriado para atender o escopo da revista.

É importante ressaltar que nossos consultores são professores ou pesquisadores com qualificação reconhecida, de instituições de ensino e de pesquisa das mais diversas regiões brasileiras e de várias áreas do conhecimento e que não recebem remuneração pelo serviço prestado.

Os nossos revisores têm responsabilidades significativas assumidas conosco: fornecer, por escrito, uma crítica cuidadosa, justa, construtiva, imparcial e informativa do trabalho submetido, com os méritos acadêmicos e o valor científico do trabalho, evitando comentários ou críticas pessoais, além de manter a confidencialidade do processo de revisão. O objetivo da revisão não é demonstrar a proficiência de quem revisa, mas colaborar com a qualidade final dos textos.

A seleção dos revisores acorre, frequentemente, com o auxílio de bancos de dados eletrônico mantido pelo próprio periódico, convidando os examinadores cuja experiência mais se aproxima ao tema do manuscrito. No processo de seleção, cuidado especial é tomado para não incorrer em questões de viés potencial de conflito de interesse. Desse modo, é solicito aos revisores que apontem quaisquer potenciais conflitos.

Os autores que submetem seus artigos ao nosso periódico têm uma razoável expectativa de que o processo de revisão permanecerá estritamente confidencial. Desse modo, o material sob revisão não pode ser compartilhado ou discutido com alguém fora do processo de revisão e da equipe responsável. No caso de um revisor ter dúvidas sobre as políticas internas de avaliação às cegas, ele deve reportar a dubiedade ao editor. O material submetido à avaliação é uma comunicação privilegiada que deve ser tratada em sigilo, com o cuidado de resguardar a identidade do autor e da obra. Os revisores não podem reter cópias dos manuscritos submetidos e não devem usar o conhecimento de seu conteúdo para qualquer propósito não relacionado ao processo de revisão. 
Os comentários e conclusões do revisor devem se basear em uma consideração criteriosa e imparcial dos fatos, excluindo preconceitos pessoais ou profissionais. Embora as avaliações sejam confidenciais, recomendamos que os comentários anônimos sejam corteses. A ReBECEM permite que comentários mais francos sejam redigidos exclusivamente ao editor. A manutenção firme desses princípios garante o sucesso de nosso processo de revisão.

Compreendemos que a nossa revista demanda um trabalho coletivo e aproveitamos nesse editorial para agradecer aos revisores da ReBECEM, os quais se dispõem ao árduo trabalho avaliativo e contribuem com a qualidade desse periódico. Além disso, esperamos que essa breve explicitação seja um convite aos leitores e autores para submeterem seus manuscritos à revista, com a plena segurança e ética do processo.

\section{Referências}

DINIS-OLIVEIRA, R. J.; MAGALHÃES, T. Reflexão sobre o estado da arte da revisão por pares. RevSALUS - Revista Científica Internacional da RACS, Coimbra - Portugal, v. 1, n.2, p.7-8, 2019. DOI: https://doi.org/10.51126/revsalus.v1i2.112. Disponível em: https://revsalus.racslusofonia.org/ojsrevsalus/index.php/RevSALUS/article/view/112/36. Acesso em 23 abr. 2021.

COIMBRA JR., C. E. A. Desafios à avaliação da literatura científica: a revisão pelos pares. Cad. Saúde Pública, Rio de Janeiro, v. 19, n. 5, p.1224-1225, set-out, 2003. Disponível em: $<$ http://www.scielo.br/scielo.php?script=sci_arttext\&pid=S0102311X2003000500001\&lng=en\&nrm=iso>. Acesso em: 23 abr. 2021. https://doi.org/10.1590/S0102-311X2003000500001.

SILVA, C. N. N.; PÖTTKER, L. M. V.; MOREIRO GONZÁLEZ, J. A. A revisão por pares: causas e consequências dos principais problemas para avaliar a qualidade. In: Encuentro Ibérico EDICIC, 7², 2015, Madrid. Actas del VII Encuentro Ibérico EDICIC, 2015, p. 1-10. Disponível em https://eprints.ucm.es/id/eprint/34689/. Acesso em: 23 abr. 2021.

SILVA, C. N. N. da; MOREIRO-GONZALEZ, J. A.; MUELLER, S. P. M. A revisão por pares a partir da percepção dos editores: um estudo comparativo em revistas brasileiras, espanholas e mexicanas. RDBCI: Revista Digital de Biblioteconomia e Ciência da Informação, Campinas, SP, v. 14, n. 1, p. 126-143, 2016. DOI: 10.20396/rdbci.v14i1.8640579. Disponível em: https://periodicos.sbu.unicamp.br/ojs/index.php/rdbci/article/view/8640579. Acesso em: 23 abr. 2021. 
Cascavel, 27 de abril de 2021.

Prof. Dr. Dartel Ferrari Lima Profa. Dra. Fernanda Aparecida Meglhioratti Profa. Dra. Rosana Franzen Leite Prof. Dr. Tiago Emanuel Klüber

Editores da ReBECEM 